May 2013

"The Birth of a Democracy: Homegrown Bicameralism in Somaliland"

Jean-Paul Azam 
May 13, 2013

\title{
The Birth of a Democracy: Homegrown Bicameralism in Somaliland
}

\author{
by \\ Jean-Paul Azam \\ Toulouse School of Economics \\ (University of Toulouse, ARQADE, IDEI)
}

\begin{abstract}
Somaliland has recently developed an unexpected democracy after seceding from chaos-ridden Somalia, while turning its port of Berbera into a success story, competing successfully with the long established ones in the Horn of Africa. A simple game-theoretic model is used to explain why the home-grown bicameral democratic system that emerged in Somaliland is a key factor in making Berbera a credible outlet for the external trade of neighboring landlocked Ethiopia. The model shows that redistributing some of the fiscal resources levied on this trade is necessary for sustaining this efficient political equilibrium.
\end{abstract}

Acknowledgements: Different preliminary versions of this paper have been presented at the Political Economy and Development workshop at the Paris School of Economics (June 5, 2010) and at the Lisbon Meeting on Institutions and Political Economy (September 8, 2011). Helpful comments by Gani Aldashev, Jean-Marie Baland, François Bourguignon, Elise Brezis, Tillman Brück, Cristian Castanhia, Justinia Fischer, Cecilia Garcia-Peñalosa, Maitreesh Ghatak, Kalle Moene, Dilip Mookherjee, Jean-Philippe Platteau, Romain Rancière, Debraj Ray, Jose Tavarès, and especially Adam Przeworski and Oliver Vanden Eynde who were the discussants, are gratefully acknowledged.

JEL Classification Numbers: P48 - O17 - O55 - N77.

Author's contact: Professor Jean-Paul Azam, Toulouse School of Economics (ARQADE, UT1-C), 21 Allée de Brienne, 31015 Toulouse Cedex 6, France.

E-mail: $\underline{\text { azam@univ-tlse1.fr }}$ 


\section{Introduction}

On June 26, 2010, about 1.09 million Somalilanders proudly cast their votes in a free presidential election ${ }^{1}$. Ahmed Mohamed Silanyo from the opposition Kulmiye Party won and the incumbent left office without any violence erupting. The election eventually took place nearly two years behind schedule, because it was technically difficult to establish acceptable lists of voters in a country where the population is mostly comprised of nomadic herdsmen who constantly cross the border back and forth with neighboring Ethiopia in search of suitable pastures. A lot of negotiation between this people's different clans was necessary to build a consensus. This process was driven by the Gurti, the Somali name for the House of the Elders. There is no formal chiefdom in the Somali clans, but the elders are traditionally exerting a significant level of authority over their members (Lewis, 2008). The Somali nomadic herdsmen are still strongly affiliated to different clans, themselves subdivided into kinship groups, under the elders' informal but firm leadership. This power was successfully harnessed to the emerging "Somaliland Republic" by creating the House of the Elders beside the standard elected House of Representatives. This upper house plays a part close to that of the British House of Lords, allowing the traditional authorities to be involved directly in the country's affairs. We argue below that this is one of the fundamental pillars of this country, as this is the key to establishing at a low upfront cost the level of security required for development. Berbera's port and the road linking it to Ethiopia’s capital city Addis Abeba are Somaliland's only reliable source of fiscal revenues. The government is in fact delegating to the elders the control of violence and banditry to protect the traders who then pay taxes in return for the country's road and port services. Then, the redistribution of fiscal revenues across regions described by Eubank (2010) is the natural compensation for the investment made by the elders in providing the key public good of a safe road.

\footnotetext{
${ }^{1}$ Appendix 1 provides some historical background about Somaliland and its path to democracy and statehood.
} 
This paper presents a framework for thinking about this unexpected success and to draw some lessons for understanding state formation in general. A simple model is used to show how Somaliland's political equilibrium is fundamentally rooted in the need to provide this security. This model sheds some light on the unusual political institutions that emerged from less than two decades of self rule following the 1991 secession. Although some limited fighting occurred for a while inside Somaliland in the early 1990s, in particular over the control of the port of Berbera and the airport of Hargeysa, the Somalilanders engaged quickly in a political process that led to a fairly successful democracy in about a decade ${ }^{2}$. What seems very important when looking at Somaliland's experience is that this gradual build-up of a functioning state started from the grassroots, with very little outside interference. Eubank (2010) emphasizes that the "Somaliland Republic" has not been recognized internationally, what makes it ineligible for foreign aid. In his view, this is an asset rather than a liability, as it forced the Somalilanders to develop accountable political institutions and to engage in state formation in a non-Eurocentric fashion. The aim of the present paper is to go one step further in analyzing the government that resulted, and in particular to explain why the "fiscal decentralization” that Eubank (2010) is looking for does not exist in Somaliland. The model argues instead that the redistribution of fiscal resources from the government to the different regions lies at the heart of these peaceful and democratic institutions. The key role of redistribution in peaceful state-building in Africa has been emphasized in particular by Azam (2006). In Somaliland, this redistribution of fiscal resources has funded a significant expansion of the education and health sectors over the whole territory. Between 1997 and 2006, the number of primary schools has risen from 165 to 516, while the number of

\footnotetext{
${ }^{2}$ A constitutional referendum took place on May 31, 2001. Then, district council elections took place in December 2002, Presidential elections in April 2003, and parliamentary elections in September 2005 (Bradbury, 2008). A new presidential election took place in June 2010 (Brumfield, Ben, and Mohamed Amiin Adow. 2010. "Polarized Somalia Marks 50 Years of Freedom from Colonial Rule.” www.CNN.com, June 26, 2010 (accessed June 27, 2010)). The incumbent lost to the opposition leader (Adow, Mohamed Amiin. 2010. "Opposition leader wins elections in Somaliland.” www.CNN.com, July 3, 2010 (accessed same day).
} 
Universities from 1 to 5 (MNPC, 2010). Eubank (2010) presents some charts showing the remarkable progress of school enrolment over a decade.

The model argues that the "Somaliland Republic" shares many features of the "Indirect Rule" system that was widely used in the British Empire, and also used in many developing countries since their independence. Boone (2003) shows how this system was successfully applied in several parts of post-colonial Francophone West Africa, where the central government delegated the control of some areas to local traditional authorities, in return for some transfers. We argue below that this system cuts through a vexing "bootstrap" problem facing all new states: you need fiscal resources to extend the state's control to various parts of the territory, but you need a fairly strong level of control to raise those fiscal resources in the first place. This problem explains why many African states exert in fact a limited effective control over their territory, leaving de facto large parts of their country without any effective state presence (Herbst (2000). We argue that Somaliland was put on the fast track to solve this problem thanks to two pre-existing assets. First, this country inherited a valuable transport infrastructure, which only required an efficient political regime to become competitive in the Horn of Africa. Ports are "the taxman's best friend”, as they provide a “choke-point" where taxable resources get concentrated and make revenue collection relatively cheap. Second, the traditional institutions of this pastoral society had not been destroyed by either the British colonial rule or the subsequent "modernizer" government of post-colonial Somalia, despite the brutal attacks by Mogadishu's government in the final years of Siyad Barre's rule in the late 1980s (Lewis, 2008). That indiscriminate violence against civilians and soldiers alike helped in fact the Somalilanders to achieve a consensus about seceding from Somalia to build their own state.

Our approach to Somaliland's state-building shares some features of the property rights approach to the theory of the firm (Hart, 1995). The returns to the transport 
infrastructure depend crucially on the "relationship-specific investments" made by the elders in controlling violence and banditry, which is in turn rewarded by some transfers. Similarly, Hart's theory rests on "incomplete contracts theory", which assumes that only a fraction of the information observed by the parties to the contract can be used as part of an enforceable contract, while the rest is not verifiable by a court. Our model pushes this to the extreme, as no third party can enforce any agreement between the government and the clans' elders. The solution offered to this commitment problem brings out the key contribution made by the present model relative to Alesina and Spolaore's theory of the size of nations (Alesina and Spolaore, 2003). The latter sees the government as a country's monopoly producer of a public good that benefits its people differentially and that cannot credibly commit to compensate people for these differences by transfers in a democracy. In the present model, the government is unable to produce the public good alone and must rely on the traditional authorities to control violence and banditry, provided their participation constraint is satisfied through a transfer. Then, the promise of this transfer is made credible in a repeated-game framework because the recipients can punish the government by reducing drastically its payoff in case of cheating. This implicit threat is credible because the recipient of the transfer is incurring a positive opportunity cost in delivering its part of the deal. Hence, what looks like a transfer is in fact the price paid for a productive service procured by the government.

The resulting political structure is a variant of the hybrid institutional structures analyzed in Bendor and Mookherjee (1987), which combine local hierarchies with various forms of decentralization. The social control exerted by the elders is a hierarchical relationship within the clan, while the assembly of the elders provides a horizontal form of cooperation between the clans. Hence, Somaliland's political organization is a non-territorial federation of clans accommodating the special constraints facing a nation of nomadic herdsmen. Moreover, Somaliland's experience suggests that a key part is played by the 
redistribution of the gains from cooperation by transfers, what is ruled out in BendorMookherjee. Somaliland's homegrown bicameralism achieves this by helping the key players to share the required information in a credible fashion and to exercise some veto power.

More generally, the state is a means to internalize a key externality to enlarge the players' opportunity set and to pay fair compensations in the state-formation theory sketched below. This is why redistribution plays a key role in African state building, where the basic negative externality is the threat of civil war, or more generally the threat of violence. If I get armed, your expected welfare goes down, as there is a non-zero probability that I will use my weapons to attack you or damage your assets. The "social contract" is preventing this by providing a fair and credible compensation for giving up one’s weapons (Azam and Mesnard, 2003). In Somaliland, the threat was looming on the economy, as any insecurity felt by the traders would have brought the port of Berbera to a halt, and it was overcome through a gradual bottom-up process leading to the emergence of democracy.

Section 2 presents the basic model, while section 3 describes the mechanisms that sustain its efficient political equilibrium. Section 4 discusses why a similar process did not take place elsewhere in Somalia and section 5 offers some brief conclusions.

\section{A Model of Traders under Threat}

After the breakup of Somalia, law and order collapsed, and the country became prey to roving bandits and warlords, making trade highly risky. However, Somaliland managed to isolate a relative safe heaven for traders. The following model brings out the two levels of political organization that made this possible. We first analyze how the traditional system of social control was mobilized for controlling violence. The next section brings out how a higher level of political cooperation was needed to create the required level of security. 


\section{The Traders}

Let $x$ be the value of the goods transported through the country. The traders potentially incur three types of costs: (i) there is first a resource cost involved in trucking the shipments, including fuel, labor, etc. (ii) then, they might be raided by bandits along the way with probability $\pi$. In this case, we assume that the bandits take everything away, leaving the trader without anything to sell at the port. (iii) Lastly, the lucky ones who have not been raided pay a tax when leaving the country at the fixed rate $t$. On the export side, we assume that the tax is paid at the port, and on the import side, at the other end of the trip, at the border $^{3}$. Assume also that the government tightly controls corruption so that the tax rate is fixed before the other agents make their decisions and does not respond to the trade flow. All the parameters of the model are assumed common knowledge, so that all the players can correctly anticipate the decisions made by the other players. The traders are assumed to play last, deciding to start the trip or not taking $t$ and $\pi$ as given.

It is realistic to rule out free entry in the trading business, mainly because of the typicaly limited warehouse capacity and restricted credit in poor countries. In Africa, longdistance traders usually belong to some long-established family networks (Grégoire and Labazée, 1993). Assuming for the sake of simplicity a quadratic cost function, the representative trader chooses Berbera rather than any other port if:

$$
E=\max _{x}(1-t)(1-\pi) x-\frac{x^{2}}{2 \theta} \geq v
$$

where $v$ is the trader's reservation profit, which he could expect to earn using an alternative route. As will become clear at (2) below, $\theta$ may be interpreted as an index of infrastructural

\footnotetext{
${ }^{3}$ This assumption is admittedly not perfectly realistic, as the tax is in reality paid at the port both on imports and on exports. The difference with the assumption made above is that in the latter case, the importers have to pay taxes even on the goods that might be stolen by the raiders on the way to the inland border. Hence, if $x / 2$ is the value of the imported goods, then the traders would incur an additional expected cost $\pi t x / 2$ compared to the case prevailing under our simplifying assumption expressed above. We neglect this in what follows, for the sake of simplicity.
} 
capacity. Then, (1) assumes that the marginal cost of trading is increasing with the pressure exerted on this capacity. From the first-order condition, the amount of trade going through the country if the weak inequality in (1) holds is:

$$
x=\theta(1-t)(1-\pi)
$$

Substituting into (1) shows that a positive level of trade will go through the country if:

$$
(1-t)(1-\pi) \geq(2 v)^{1 / 2} \theta^{-1 / 2}
$$

If $\theta>2 v$, (2) and (3) jointly imply that the level of trade will then be such that:

$$
(2 v \theta)^{1 / 2} \leq x \leq \theta
$$

Otherwise, it falls to zero. This simple setting captures the idea that Berbera's competitiveness depends first on $v$ and $\theta$, which determine respectively the profitability of doing business with the competitors and the physical transport cost inside the country, and then on two choice variables, $\pi$ and $t$, which are determined respectively by the bandits and the tax authority. In what follows, we assume that $\theta$ is much larger than $2 v$, in order to capture the geographical advantage of Berbera over its competitors. Then, Berbera should win, provided the two key players manage to put their act together efficiently.

\section{The Potential Bandits and the Government}

Let us first analyze how the bandits would behave in a hypothetical society where the traditional clanic authorities would fail to organize their activity. The simplest assumption regarding the cost of raiding the traders is that a fraction $0<\gamma<1$ of the shipment is lost in the raiding. This might capture the collateral damage of any fighting between the bandits and the traders or any other form of cost that the bandits incur in raiding. Most results below are robust to several extensions of this assumption. Given this cost function, the representative bandit seeks to maximize his expected profit:

$$
B^{R}=\max _{\pi, x} \pi(1-\gamma) x
$$


This expression implies that the bandits incur no cost at all if $\pi x=0$, either because there is no traffic to attack or they are not performing any raiding. When the bandits are not organized, they do not take into account the externality they inflict on other bandits when performing an attack, namely that this tarnishes the road's reputation and thus reduces the traffic by increasing the traders' expected loss. It is then easy to check that this "roving bandit” equilibrium predicts that no traffic at all uses the country' transport services:

$$
\pi^{R}=1 \text { and } x^{R}=0 .
$$

Against this background, we can now analyze the first contribution made by the coalesced Elders in reducing banditry. In this nomadic society, where the young men are spread all over the land in search for pasture, collective identity is defined by genealogy rather than by reference to a territory. Moreover, herdsmen could fight a dispute over grass or water at any time and escalation is prevented by the institution of "blood compensation", or diya in the Somali language. This is a clever system creating joint liability within the group of origin of the perpetrator of a violent crime, as the whole group is responsible for paying the compensation required by the victim's group for settling the issue. According to Bradbury (2008), the diya for the murder of one man is 100 camels (half of this for one woman), which is a very high cost for the group. If the diya is not paid the aggrieved group is committed to launch a war against the criminal's one since time immemorial. This provides a strong incentive for those who can control their fellow clan members, so that any man found guilty of a crime against a member of another clan would be punished by his own clan, thereby avoiding inter-clanic violence as far as possible. This gives the elders a key role in the Somali society’s control of violence. This power was gradually aggregated in Somaliland during the political build up towards democracy by organizing first a large series of local meetings of elders, which then developed in a pyramidal fashion, culminating with the creation of the 
national assembly of the elders at the Gurti (Bradbury, 2008). This process was mainly organized and funded by the Diaspora who had fled the repression under Siyad Barre.

Let us first see what such a consolidation process could deliver within our model society with traders and bandits. Quite obviously, the resulting syndicated banditry could internalize the negative externality on trade flow created by raiding. Instead of problem (5), this coalition would maximize:

$$
B^{S}=\max _{\pi, x} \pi(1-\gamma) x \text {, s.t. } x=\theta(1-t)(1-\pi) \text {, }
$$

Resulting in the following levels of raiding and traffic:

$$
\pi^{S}=1 / 2 \text { and } x^{S}=\theta(1-t) / 2 .
$$

Hence, forming a coalition of clans is not sufficient to explain why raiding would stop. Nevertheless, the creation of an institution that helps the clanic traditional authorities to coordinate their action improves efficiency by reducing raiding and increasing traffic.

Now, absent any political arrangement that could help the government and the syndicated bandits to coordinate their action, the government would simply maximize its expected fiscal revenues, taking into account the traders' best-response function (2) and the bandits’ best choice:

$$
G=\max _{t, x} t(1-\pi) x \text {, s.t. } x=\theta(1-t)(1-\pi) .
$$

Proposition 1 below describes the Nash equilibrium prevailing in this model when the two players do not coordinate their actions through any political arrangement.

Proposition 1: The uncoordinated Nash equilibrium choice of $\pi$ and $t$ by the government and the syndicated bandits, respectively, is:

$$
t^{N}=\pi^{N}=1 / 2,
$$

entailing a level of traffic:

$$
x^{N}=\theta / 4,
$$


and the following payoffs for the bandits and the government, respectively:

$$
G^{N}=\theta / 16 \text { and } B^{N}=(1-\gamma) \theta / 8 \text {. }
$$

The next section shows how a more inclusive political arrangement can harness the social-control mechanism provided by the traditional authorities to reduce raiding to zero.

\section{Fiscal Redistribution in the Efficient Political Equilibrium}

In a clanic society, genealogy is the essence of social identity, and the elders value the continuation of the clan, and thus care for the next generation's welfare. This can be captured by a dynastic family model à la Barro (1974), where the next generation's welfare enters the current generation's utility function, thus creating a chain of inter-generational links up to infinity. Choi and Bowles (2007) show how such externality, which they call "parochial altruism”, is an important asset for human groups' survival in a violent world, within an evolutionary framework. This assumption is appropriate for a traditional clanic society like the Somali one. We thus discuss the political setting in which banditry can be eradicated by embedding the previous section's model in an infinite-horizon repeated game framework. We then show how Somaliland's political institutions cater for the key mechanisms brought out by this model.

\section{The Efficient Political Equilibrium}

Let $0<\delta^{B}<1$ and $0<\delta^{G}<1$ be the bandits'- and the government's discount factors, respectively. Then, assume that the government and the coalition of elders bargain at each period over the value of a transfer $g>0$ to be paid by the government if the bandits refrain from raiding the traders, i.e., if the elders enforce $\pi=0$. This implicit contract entails that the potential syndicated bandits are acting first and the government second, by delivering the transfer after observing that the raiding was avoided, but there is no third party to enforce the government' promise to pay. We define an efficient political equilibrium as an efficient 
outcome that can be sustained ad infinitum in the repeated game between the government and the potential bandits ${ }^{4}$.

Definition 1: An efficient political equilibrium is a triplet $\{t, \pi, g\}$ that (i) lies on the Pareto frontier of the game between the government and the potential syndicated bandits, and (ii) can be sustained by a standard trigger-strategy equilibrium.

In this simple setting involving a transfer, the Pareto-efficient $\{t, \pi\}$ pair can be derived by solving the following problem:

$$
\max _{t, \pi} W=[t(1-\pi)+\pi(1-\gamma)] x \text {, s.t. } x=\theta(1-t)(1-\pi) \text {. }
$$

Then the following lemma is proved in appendix 2:

Lemma 1: The Pareto-efficient outcome implies the following values for $\{\pi, t, x\}$ :

$$
\pi^{*}=0, t^{*}=1 / 2 \text { and } x^{*}=\theta / 2 \text {. }
$$

The intuition for this result is straightforward as the unit cost $\gamma>0$ makes raiding an inefficient way of collecting revenues from the traders. This entails that the government will perform all the revenue collection in the efficient equilibrium where the chosen tax rate maximizes the Laffer curve $t(1-t)$ as in the previous section's Nash equilibrium, while the bandits will stay put. Then, the traffic level is twice as large in this equilibrium as in that uncoordinated Nash equilibrium.

We can now prove the following:

Proposition 2: There exists at least one efficient political equilibrium with:

$$
(1-\gamma) \theta\left(\frac{4-3 \delta^{B}}{8}\right) \leq g^{*} \leq \frac{3 \theta \delta^{G}}{16}
$$

if:

\footnotetext{
${ }^{4}$ We do not model the precise bargaining process and we thus leave the exact value of the transfer undetermined. We focus instead on finding the conditions for the bargaining set not to be empty.
} 


$$
\delta^{G} \geq \underline{\delta}^{G}=\frac{2(1-\gamma)}{3} \text { and } \delta^{B} \geq \underline{\delta}^{B}=\frac{5-8 \gamma}{6(1-\gamma)}
$$

and:

$$
\delta^{G} \geq(1-\gamma)\left(\frac{8-6 \delta^{B}}{3}\right)
$$

The proof is in appendix 2. The key point that sustains this equilibrium is the credibility of the two implicit threats made by the two sides: (i) if the government defaults on the transfer, then the bandits will inflict a cost for ever after by raiding the traders and reducing the level of traffic that can be taxed. This is credible because restraint is costly for them; (ii) if the bandits attack the convoys the government will withhold the transfer for ever after, including the current period. Because all the parameters are assumed common knowledge, these threats do not need to be made explicit. Conditions (16) and (17) show the lower bounds for $\delta^{G}$ and $\delta^{B}$ that ensure that the range of acceptable values for the transfer $g$ is not empty. If either one of $\delta^{G}$ and $\delta^{B}$, or both of them, happened to fall below these lower bounds, then the efficient political equilibrium would not exist, because the government would deem the price to pay the syndicated bandits for security too high. Notice that the second part of (16) on the right, relating to $\delta^{B}$, is trivially satisfied if $\gamma \geq 5 / 8$, so that even very short-sighted potential bandits would abide by the political agreement if their raiding costs were prohibitively high, provided the government kept its word too.

\section{Robustness and Relevance}

Figure 1 helps us to get a more intuitive grasp of this set of conditions. The two players' discount factors $\delta^{G}$ and $\delta^{B}$ are measured along the two axes, and the downward sloping line represents the lower bound of (17). The set of $\left\{\delta^{G}, \delta^{B}\right\}$ pairs that are consistent with existence of the efficient political equilibrium is labeled "acceptable triangle”. This 
assumes that $\gamma \leq 5 / 8$, otherwise the set of acceptable parameters is quadrilateral. Notice that this acceptable parameters' set cannot be empty as $\lim _{\gamma \rightarrow 0} \underline{\delta}^{G}=2 / 3<1$.

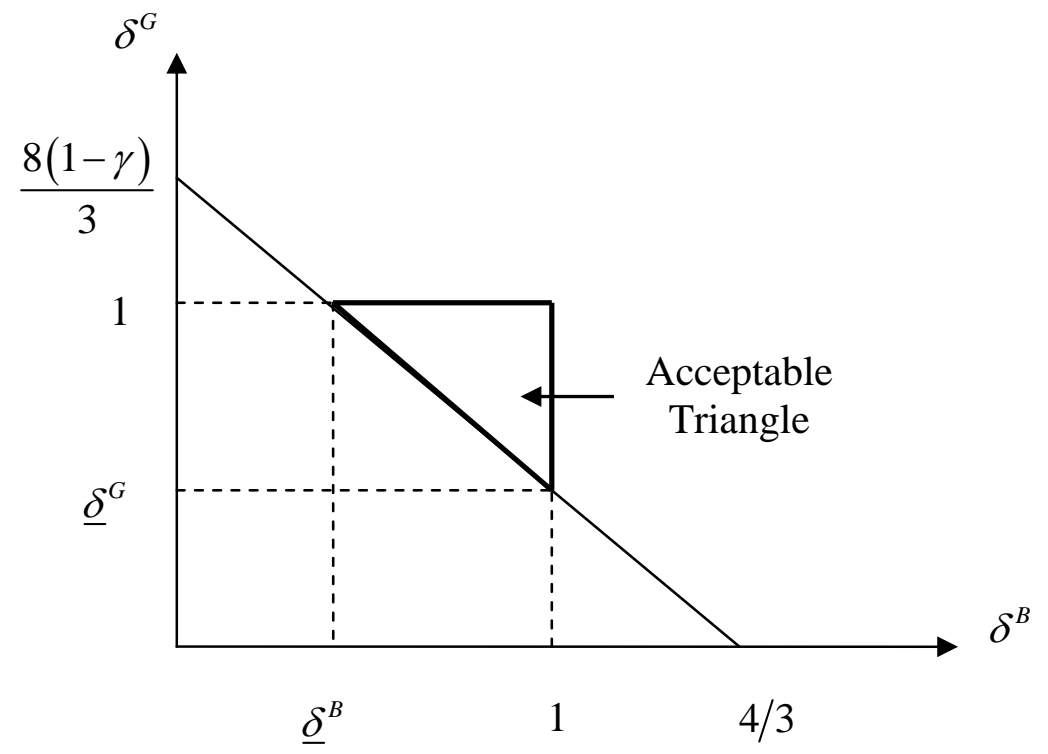

Figure 1: The Acceptable Parameter Set

In the case of Somaliland, because of the importance of genealogy as a social identifier and of ethnic homogeneity, we expect $\delta^{G}$ and $\delta^{B}$ to be very close to one another and pretty high. However, it is interesting to notice in the more general case that even a fairly shortsighted government, with a low $\delta^{G}$, would abide by the political agreement if $\gamma$ was high enough and $\delta^{B}$ was close enough to 1 . This emphasizes the importance of the government's relative efficiency at collecting resources from the traders compared to raiding by the bandits, because it determines the level of transfer required to buy security. Inefficient bandits are cheaper to buy off than efficient ones. The two sides need to be closer in terms of $\left\{\delta^{G}, \delta^{B}\right\}$, the further away is $\delta^{B}$ from 1 , as long as $\delta^{B} \geq(1-\gamma) 8 / 3(3-2 \gamma)$, and the lower is $\gamma$. The opposite case holds too, where a very long-sighted government, e.g., a hereditary monarchy, could sustain the efficient political equilibrium even if the potential bandits had a very low $\delta^{B}$, e.g., because of a high mortality rate, provided $\gamma$ was high enough. 
The foregoing modeling exercise thus suggests that the conditions bearing on the parameters for the efficient political equilibrium to exist are not too restrictive. Then, this model sheds some light on Somaliland's political institutions. The key problem to be solved was for the business-oriented elite to delegate to the traditional authorities the task of controlling violence and banditry effectively so that Berbera became an attractive outlet for the traders from Ethiopia as well as for livestock exports. The first step was to help the clans' elders to cooperate by organizing several local conferences, but the model shows that this is not enough to provide the incentives for reducing banditry to zero. The second step was aimed at making credible the promise of transferring a share of the enhanced fiscal resources resulting from the increased trade flow to the clans. A bicameral system was put in place to ensure that the elders had a key role in the law-making process, by giving them a direct access to the required information, as well as some veto power in the implicit bargaining problem. As seen in the introduction, the redistribution of the fiscal resources was focused on the development of the education and health sectors in all the regions, as one would expect in a country where genealogy is the key social identifier that determines each person's affiliation to a clan. The dynastic family model explains why people felt compensated for their efforts by seeing their children getting some medical protection and going to school and university.

\section{Why Not the Rest of Somalia?}

The previous section begs the question of why such an efficient political equilibrium did not emerge in the rest of Somalia. One answer is given by Eubank (2010), who claims that foreign aid played a detrimental role there by relaxing the need to build accountable institutions in that part of the country. Within the model's framework, this was yielding a good substitute for fiscal revenues that was independent on the elders' provision of security. Another easy culprit is the interference of foreign powers, including Ethiopia and the US 
behind it, emphasized by Lewis (2008). It is worth going into more detail to look at the missed opportunities in eastern and southern Somalia.

Without formally declaring secession, the northeastern part of Somalia built up also a bottom-up institutional solution as the "New Puntland State of Somalia", founded at a conference in Garowe in 1998. This promising solution started among some Darod clans, in particular among the Mijerteyn (Lewis, 2008), but it was missing two of the key ingredients of Somaliland's success. First, that part of the country did not inherit an infrastructural asset of the same caliber as the port of Berbera and really had very little infrastructure instead. The Puntland's ruling elite never lost sight of the nearby formal capital-city in Mogadishu in the south, where the infrastructural assets are located, mostly built during the colonial period, despite the massive destruction brought about by the war. Mogadishu has two ports and an international airport, and a road to Addis Abbeba called the "Strada Imperiale", which could be restored. Hence, the Puntlanders never severed their links to the rest of Somalia, realizing probably that they would never be able to levy the fiscal resources required to cement a social contract like in Somaliland. Their strategy was instead to regard the "New Puntland State" as a building block to reconstruct Somalia. Second, they created a mono-cameral parliament, without any institutional representation of the elders. In the terms of the previous section, this might be blamed on the lack of significant transport infrastructures, and thus on the lower need for security. This is illustrated by the fact that piracy is quite active off the coast of Puntland, imposing a negative externality on all the ports of the Red Sea and the Gulf of Aden. However, the failure to give the elders a large enough role in the New Puntland State is also probably due to the towering figure of Col. Abdillahi Yusuf, who assumed first the Presidency in Puntland, up to 2001, and then won the Federal Presidency in Mogadishu. He obviously failed to draw the lessons of Siyad Barre's military regime’s failure to create topdown a viable state in Somalia before the breakup, as he tried also to impose his authoritarian 
rule on the New State of Puntland. However, the "rule of fear" also requires resources, which are dramatically lacking in Puntland, while they are somewhat higher in Mogadishu, if only because of foreign aid as mentioned above.

Southern Somalia once had the resources to support Siyad Barre's authoritarian government, which had a very destructive strategy against the traditional clan system. For a while, his government was aligned with the Soviet Union, before alliances switched, and the USA became involved. Although southern Somalia inherited a valuable infrastructural asset at independence, in addition to the sovereignty rent due to international recognition and foreign aid, it was facing a more complicated political problem than Somaliland. Southern Somalia has a sizable agricultural area, between the Shabelle and Jubba rivers where the Somali clans have a distinct sedentary culture, in which territory matters at least as much as genealogy, so that the elders have a weaker role in social control than in the other two regions. Moreover, there are Bantu farmers in the midst of this Somali population, loosening further the ethnic ties in that part of Somalia. They first came there as slaves but are nowadays mainly acting as independent farmers. Hence, the traditional authorities are too weak in that part of Somalia for delivering the kind of social-control services available in Somaliland, on the one hand, while the government was too authoritarian to make credible promises of redistribution, for lack of checks and balances, on the other hand. Moreover, foreign aid was making the need for a cooperative solution less pressing and the latter has never been tried.

A temporary solution emerged recently in that land dominated by the warlords when the Islamic Courts took over. As emphasized in particular by Roberts (2003), the main reason why political Islam is enjoying so much popular support in Muslim countries is that it promises to impose an equal rule of law for all via the Sharia law, in stark contrast to Somalia's domination by warlords and bandits. These Islamic courts managed to take over in Mogadishu, ousting the warlords from the city and its infrastructures, and starting to restore 
the port and the airport. However, the US government and its Ethiopian allies feared that these courts had links with Al Qaeda, and helped some warlords to regain control of the city with the support of the Ethiopian army (Lewis, 2008). The Islamic peace then broke down and hundreds of civilians fled the city again, as the latter was returning to the previous chaos. Whether this is just one example of the counter-productive effects of external interference in Southern Somalia as claimed by Bradbury (2008) and Lewis (2008) is debatable. The lethal attacks perpetrated in June and July 2010 in Somaliland and in Uganda by the Al Shabaab group, which then controlled most of central and southern Somalia, undoubtedly seem inspired by Al Qaeda's style ${ }^{5}$, suggesting that such links exist. Moreover, the emergence of such a radical Islamist group might be a response to chaos, as no such thing happened in democratizing Somaliland, suggesting that reverse causation might exist here.

According to Bradbury (2008) and Lewis (2008), the most shocking manifestation of dysfunctional external interference is provided by the endless series of recurrent UNsponsored peace conferences, where the wrong people are repeatedly invited. According to Bradbury (2008) the UN keeps inviting people who have irreversibly destroyed their reputation by collaborating with the pre-civil war dictatorship and who are unable to deliver the services provided by the clans' elders in Somaliland, as they are completely cut off from the true social fabric of the Somali society. Bradbury (2008) suggests that these conferences are only meant to further some UN officers' careers, without any hope of solving any problems in Somalia. Probably, the best response to this line of criticism would be to screen participants in these conferences according to the social-control services that they can deliver effectively, along the lines suggested by the experience of Somaliland.

\footnotetext{
${ }^{5}$ Armstrong, Paul. 2010. “Somali militants ready to terrorize world ?”www.CNN.com, July 13, 2010 (accessed the next day).
} 


\section{Conclusion}

The case study performed above of the emerging "Somaliland Republic", which is as yet unrecognized internationally, provides a natural experiment shedding some useful light on the theory of state building. It shows that the Hobbesian Leviathan is not the only path for controlling violence and building up a peaceful state. It suggests that a Lockean "horizontal social contract" model may be a viable solution in some circumstances, for "breaking up" a state of anarchy (Hirshleifer, 1995). In Somaliland, we observe a separation of the clans' elders' power to control violence, on the one hand, and the modern state's power to tax and to produce some of the public goods, on the other hand. Among other things, this study shows how the social anthropologists' work can help us to understand the political economy of developing countries. In return, our modeling exercise demonstrates the key part played by an inherited infrastructural asset, namely Berbera’s port and the road that links it to Ethiopia.

This model is an extension of Hart's "Property Rights Approach" to the theory of the firm (Hart, 1995). The clanic authorities can provide security, an asset that enters the production function for transport services as a complement to infrastructure. This insight is fundamental for understanding why a bicameral democratic institution lies at the heart of Somaliland's political institutions, for providing a balanced representation of the traditional authorities and of the business-oriented modern actors. Somaliland's experience also provides a fruitful line of arguments in favor of a qualified support for the traditional "project aid" doctrine, with its emphasis on funding infrastructural projects, which has inspired the action of the World Bank and other development agencies for decades. The qualification brought out here is that a correct political setting is required, aimed at making the redistribution of the benefits from cooperation among the different actors credible. This redistribution is the compensation due to the potential bandits for refraining from raiding the traders and thus participating in the efficient political equilibrium. In contrast, the inability to set up a correct 
political system in the rest of Somalia, partly because of external interference but more fundamentally because of unfavorable initial conditions, is making the infrastructural assets of southern Somalia pretty useless for producing the peace. Similarly, the rent to sovereignty provided by the foreign aid that comes with international recognition is not contributing much to that end at present.

The state-formation theory presented in this paper is well suited for explaining other cases of political settlements elsewhere in Africa. For example, the role of some transport infrastructure in sustaining a peace process is evident in the case of Sudan. There the key infrastructure has been the pipeline that brings the oil extracted in the south to the Red Sea and the world market via Port Sudan in the north since 1999. For centuries, the northerners have been raiding the south for capturing slaves and civil war prevailed for decades between these two groups after independence (Burr and Collins, 2008). Then, alliances switched as oil was found in the south and became the country's key asset, and the Northerners sought for peace after the Southerners had blown up the pipeline (Jok, 2007). A power-sharing agreement was established soon after the required collaboration for keeping the oil flowing was thus made obvious (Natsios, 2012). The downside of this mechanism is that the new political equilibrium excludes the ethnic groups whose territory is too remote from the pipelines to exert any credible threat. This is why the Sudanese government is violently cutting off its ties with its former allies from Darfur (Cockett, 2010). The peace between the north and the south has survived the secession of South Sudan in 2011, as the pipeline still forces the two sides to cooperate. This example illustrates vividly how transport infrastructures play a key role in determining the politically-sustainable boundaries of the states when their efficiency depends on the goodwill of the people living around them.

Appendix 1: Historical Vignette. Somaliland is a former British protectorate on the southern shore of the Gulf of Aden, which seceded unilaterally from Somalia in 1991 after 
trying for three decades to create a unified country with the latter. Its population is estimated at about 3.5 million people. It has two main physical assets, namely its grazing land and livestock, on the one hand, and its transport infrastructures, on the other hand. The latter include mainly the port of Berbera and the airport of Hargeysa, its capital city, as well as their connecting roads. The herdsmen need the port of Berbera for exporting their livestock to the Arabian Peninsula and other countries in the Middle East, which are their main outlet. Moreover, Berbera gives a convenient access to the Indian Ocean to neighboring landlocked Ethiopia, and there is a main road between the two ${ }^{6}$. Berbera's traffic has been rising steadily over the past decades. For example its traffic of import containers has nearly doubled between 2003 and 2007 (MNPC, 2010). This port's promising position is confirmed by the fact that Bolloré Africa Logistics, the biggest port operator in Africa, has made public in 2010 its project of investing massively in Berbera's port and its transport corridor with the Ethiopian capital-city Addis Abbeba ${ }^{7}$.

The Ogaden province across the border in Ethiopia is also peopled by Somali-speaking herdsmen, and that border is fairly porous, as the best grazing land called the Haud is straddling it $^{8}$. Refugees have also crossed this border back and forth over the past decades, depending on the changing intensity of fighting during the Ethiopian civil war, which ended in 1991, and the one in Somalia ever since. While ethnically homogenous, these Somalispeaking people of Djibouti, Ethiopia, Kenya, Somalia and Somaliland are traditionally affiliated to different clans that straddle these countries' borders, which might at times enter into violent conflict against one another. The chaos that prevails in most of Somalia ever since the collapse of the state in 1991 testifies that the threat of violence is looming large over this people. Siyad Barre's military government had launched an unsuccessful invasion of the

\footnotetext{
${ }^{6}$ Markakis (1992) provides a regional perspective on the ports in the Horn of Africa.

7 WorldCargo News online, March 15, 2010. "Bolloré proposes Berbera-Adis Ababa Transport Corridor". www.worldcargonews.com (accessed July 2, 2010, reproduced from Medeschi, December 10, 2009).

${ }^{8}$ See map 6.1, p.101 in Doornbos, 1993.
} 
Ogaden region in 1978 and eventually signed a shameful peace agreement with the Mengistu regime in 1988. Many military officers from the north, mainly from the Isaaq clan, the largest one in Somaliland, accused Siyad Barre of having mishandled the operations. They felt that the conquest of a more limited area in the Ogaden, including mainly the grazing land used by the Isaaq clan, could have been a success. This opposition triggered a full-blown civil war in Somalia, resulting in a coup d'état that toppled the military regime in 1991. Chaos ensued, and Somalia collapsed into a stateless entity dominated by banditry and warlordism. In contrast, Somaliland managed to develop the port of Berbera and to enforce an acceptable level of security on the paved road linking it to Ethiopia in the two decades after secession. A large share of Ethiopia's international trade is now shipped via this port.

\section{Appendix 2. Proofs.}

Proof of Lemma 1: Substituting for $x$ in (13) yields:

$$
W=\theta(1-t)(1-\pi)[t(1-\pi)+\pi(1-\gamma)]
$$

Its derivatives with respect to $t$ and $\pi$ are:

$$
\begin{aligned}
& \frac{\partial W}{\partial t}=\theta(1-\pi)[(1-2 t)(1-\pi)-\pi(1-\gamma)], \\
& \frac{\partial W}{\partial \pi}=\theta(1-t)[(1-\gamma-2 t)-2 \pi(1-\gamma-t)] .
\end{aligned}
$$

We use a technique similar to a phase diagram to prove that $t=1 / 2$ and $\pi=0$ is the unique optimum although $W$ is not concave in the whole $\{\pi, t\}$ space. Define the two loci $\pi_{t}$ and $\pi_{\pi}$ as the functions of $t$ such that (A.2) and (A.3), respectively, are equal to zero:

$$
\frac{\partial W}{\partial t}=0 \text { if } \pi=\pi_{t} \equiv \frac{1-2 t}{2-\gamma-2 t} \text { and } \frac{\partial W}{\partial \pi}=0 \text { if } \pi=\pi_{\pi} \equiv \frac{1-2 t-\gamma}{2(1-\gamma-t)}
$$

Both loci have strictly negative slopes in the relevant range and we can prove that $\pi_{t}>\pi_{\pi} \forall t \in[0,1 / 2]$. The loci intersect the axes as shown in figure A.1, i.e., with $\pi_{t}$ lying 
further from the origin than $\pi_{\pi}$. Then the above inequality could only be wrong if the two loci intersected twice for $0<t \leq(1-\gamma) / 2$. However, it can be checked that:

$$
\pi_{t}-\pi_{\pi}=\frac{\gamma(1-\gamma)}{2(2-\gamma-2 t)(1-\gamma-t)}>0 \text { if } t<1-\gamma
$$

Hence, no intersection exists between $\pi_{t}$ and $\pi_{\pi}$ in the relevant range.

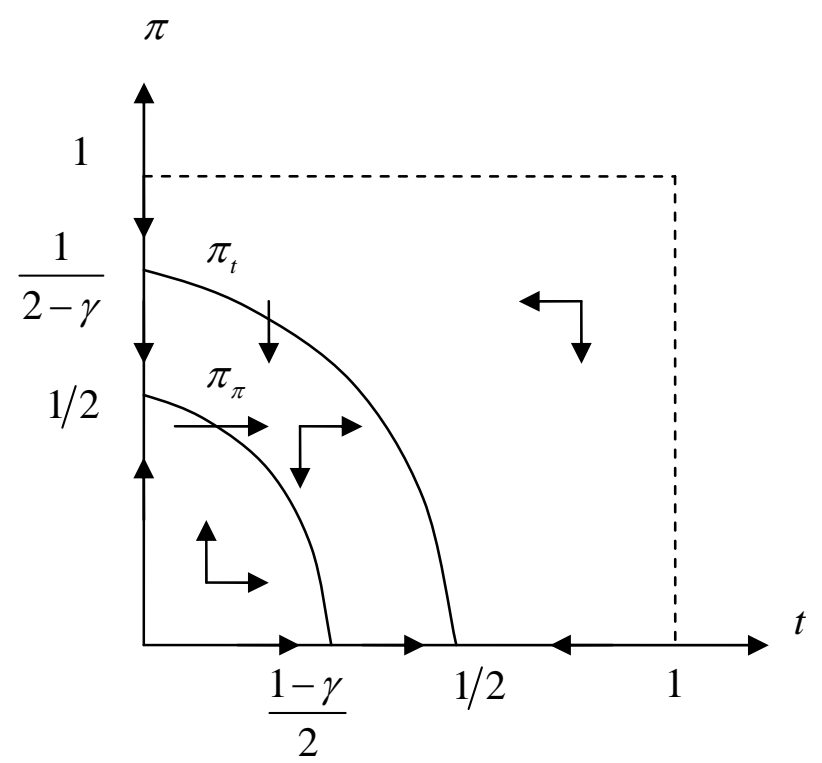

Figure A.1: Determination of the Optimum

Then, these two loci divide the relevant range of the $\{\pi, t\}$ space into three zones where the signs of $\partial W / \partial t$ and $\partial W / \partial \pi$ are liable to change. We depict the signs of these derivatives by arrows pointing in the direction of the changes in $\pi$ or $t$ that increase $W$.

Then, we identify easily two potential candidates for the optimum, namely $E_{1}=\{t=1 / 2, \pi=0\}$ and $E_{2}=\{t=0, \pi=1 / 2\}$. However, $E_{1}$ is a (one-sided) saddle point from which $W$ increases monotonically as $t$ increases monotonically and $\pi$ decreases monotonically, i.e., as one moves to the south-east within the corridor between the two loci. This leaves $E_{2}$ as the unique optimum. 
Proof of Proposition 2: Assume that both players adopt the standard trigger strategy (see e.g., Gibbons, 1992). If they choose to cooperate and refrain from raiding the traders in the hope of getting a transfer from the government $g$, the potential syndicated bandits get the following present value:

$$
V^{C}=\frac{g}{1-\delta^{B}}
$$

If they choose instead to deviate and attack the traders, the syndicated bandits will be punished first within the same period, as the government withholds the transfer $g$, and the static Nash equilibrium outcome will then prevail ever after. Assuming that this deviation was not expected by the traders in the first period, this yields the following present value:

$$
V^{D}=\frac{(1-\gamma) \theta}{2}+\frac{\delta^{B}(1-\gamma) \theta}{8\left(1-\delta^{B}\right)}
$$

The potential bandits will thus refrain from raiding the traders if $V^{C} \geq V^{D}$, i.e. if:

$$
g \geq(1-\gamma) \theta\left(\frac{4-3 \delta^{B}}{8}\right)
$$

On its part, if the government chooses to cooperate, i.e., to deliver the agreed amount $g$ when observing $\pi=0$, it gets the following present value:

$$
W^{C}=\frac{\theta-4 g}{4\left(1-\delta^{G}\right)} .
$$

If it chose instead to withhold the transfer in spite of the potential bandits' compliance with the promised $\pi=0$, the government would first keep the whole fiscal revenue in the current period, and then get its Nash-equilibrium payoff $G^{N}$ from then on. This yields the following present value:

$$
W^{D}=\frac{\theta}{4}+\frac{\delta^{G} \theta}{16\left(1-\delta^{G}\right)}
$$

Then, the government will cooperate if $W^{C} \geq W^{D}$, i.e. if: 


$$
g \leq \frac{3 \theta \delta^{G}}{16} .
$$

Hence, (A.8) and (A.11) give us the range of values of the transfer $g$ that can sustain the efficient equilibrium and conditions (16) and (17) ensure that this range is not empty.

\section{References:}

Alesina, Alberto, and Enrico Spolaore. 2003. The Size of Nations. Cambridge, MA: MIT Press.

Azam, Jean-Paul. 2006. “The Paradox of Power Reconsidered: A Theory of Political Regimes in Africa.” Journal of African Economies, 15 (1): 26-58.

Azam, Jean-Paul, and Alice Mesnard. 2003. "Civil War and the Social Contract.” Public Choice, 115 (3): 455-475.

Barro, Robert J. 1974. “Are Government Bonds Net Wealth?” Journal of Political Economy, 81: 1095-1117.

Bendor, Jonathan, and Dilip Mookherjee. 1987. "Institutional Structure and the Logic of Ongoing Collective Action.” American Political Science Review, 81 (1): 129-154.

Boone, Catherine. 2003. Political Topographies of the African State. Territorial Authority and Institutional Choice. Cambridge: Cambridge University Press.

Bradbury, Mark. 2008. Becoming Somaliland. African Issues. London: Progressio.

Burr, J. Millard, and Robert O. Collins. 2008. Darfur. The Long Road to Disaster. Princeton: Markus Wiener.

Doornbos, Martin. 1993. "Pasture and Polis: The Roots of Political Marginalization of Somali Pastoralism.” In Conflict and the Decline of Pastoralism in the Horn of Africa, edited by John Markakis, 100-121. Basingstoke: Macmillan.

Cockett, Richard (2010): Sudan. Darfur and the Failure of an African State, New Haven: Yale University Press. 
Eubank, Nicholas. 2010. "Peace-Building without External Assistance: Lessons from Somaliland.” Center for Global Development Working Paper 198: Washington, D.C.

Gibbons, Robert. 1992. Game Theory for Applied Economists. Princeton, N.J: Princeton University Press.

Grégoire, Emmanuel, and Pascal Labazée (ed.). 1993. Grands Commerçants d’Afrique de l'Ouest. Paris: Karthala-Orstom.

Hart, Oliver. 1995. Firms, Contracts, and Financial Structure. Clarendon Lectures in Economics. Oxford: Oxford University Press.

Herbst, Jeffrey. 2000. States and Power in Africa. Comparative Lessons in Authority and Control. Princeton, NJ: Princeton University Press.

Hirshleifer, Jack. 1995. “Anarchy and its Breakdown.” Journal of Political Economy, 103 (1): 26-52.

Jok, Jok Madut. 2007. Sudan. Race, Religion, and Violence. Oxford: Oneworld.

Lewis, Ioan M. 2008. Understanding Somalia and Somaliland. New York: Columbia University Press.

Markakis, John. 1992. “The Regional Significance of Sea Ports in the Horn of Africa.” In Beyond Conflict in the Horn, edited by Martin Doornbos, Abdel Gaffar M. Ahmed, and John Markakis 130-131. London: James Currey.

MNPC. 2010. Somaliland in Figures 2009. Hargeysa: Ministry of National Planning and Coordination.

Natsios, Andrew S. 2012. Sudan, South Sudan, and Darfur. What Everyone Needs to Know, New York: Oxford University Press.

Roberts, Hugh. 2003. The Battlefield Algeria 1988-2002. Studies in a Broken Polity. London: Verso. 